\title{
Application of Response Surface Methodology for Chloride Transport Properties in Nano Metaclayed-UHPC
}

\author{
M.F. Md Jaafar ${ }^{*}$, M.N. Muhd Sidek2,3, H. Mohd Saman², K. Muthusamy', N. Ghazali1 and A. Ibrahim² \\ ${ }^{1}$ Faculty of Civil Engineering Technology, Universiti Malaysia Pahang, 26300 Pahang, Malaysia \\ ${ }^{2}$ School of Civil Engineering, Collage of Engineering, Universiti Teknologi Mara, 40450 Selangor, Malaysia \\ 3nstitute for Infrastructure Engineering \& Sustainability Management, Universiti Teknologi Mara, 40450 Selangor, Malaysia
}

\begin{abstract}
The major concern on the deterioration of reinforced concrete structure is due to the corrosion of steel reinforcement from the aggressive environment such as chloride penetration. Ultra-high performance concrete (UHPC) is an advanced concrete material having ultra-high strength with excellent durability properties. Inclusion of nano metaclay in UHPC is expected to overcome the chloride transport properties in UHPC by providing nano filler effect. Two (2) assessments were conducted which are chloride content and chloride depth were examined. All the concrete specimens were immersed in $3 \% \mathrm{NaCl}$ solution up to 365 days and the tests conducted were performed at $3,7,28,56,91,182$ and 365 days. Response surface method (RSM) was performed to evaluate the interaction and relationship between operating variables (compressive strength and nano metaclay content). Based on RSM analysis, inclusion of nano metaclay in UHPC have good relationship towards the chloride resistance characteristics and adequate durability performance in terms of chloride penetration resistance. The results exhibited that inclusion of $1 \%$ nano metaclay significantly and positively affect in term of chloride penetration resistance.
\end{abstract}

ARTICLE HISTORY

Received: $19^{\text {th }}$ July 2021

Revised: $31^{\text {st }}$ July 2021

Accepted: $05^{\text {th }}$ Aug 2021

KEYWORDS

Chloride Transport

Ultra-high Concrete

Nano Metaclay

Response Surface

Compressive Strength

\section{INTRODUCTION}

Today, there is a general trend to replace Portland cement with supplementary cementitious materials (SCM) either micro based or nano based materials as additive in concrete to increase the durability of concrete. Fundamentally, concrete containing SCM as additive will be better in terms of chloride resistant characteristic. It is well-documented that utilization of high performance concrete (HPC) and ultra-high performance concrete (UHPC) are recommended to solve the chloride penetration issue in concrete [1]. Numerous researchers also highlighted that replacement of Ordinary Portland cement (OPC) by nano materials as cement replacement such as zeolite, pulverized fuel ash, fly ash, silica fume and metakaolin would increase the strength of concrete thus, improve the chloride resistance of the concrete [2-6]. They expressed the opinion that the use of nano material in concrete production can reduce the pore size of concrete. As a result, concrete become denser and strength of concrete increased. Consequently, the nano size of the materials shows significant beneficial effect to slow down the amount of chloride penetrates into concrete and reduce the chloride depth. High fineness of nano materials resulting more discontinuous pore structure produced in concrete $[7,8]$. They also pointed that the amount of chloride in the UHPC is low and very high resistance to chloride attack. In comparison, Ferdosian \& Camões [9] recorded no chloride depth in UHPC containing micro silica and fly ash after the specimen was exposed to chloride for 28 days.

Other researcher [10] also noticed that the depth of chloride penetrated in silica fume based UHPC was only $3 \mathrm{~mm}$ after 90 days of exposure. This is in contrast to Pernicová [11] who found that the chloride depth in UHPC incorporated micro silica blended with fly ash was about $10 \mathrm{~mm}$ from the surface concrete after exposure to sodium chloride for 90 days. This phenomenon commonly known due to the nucleation effect of the silica fume. The hydration of cement can be promoted and newly generated $\mathrm{C}-\mathrm{S}-\mathrm{H}$ gel was formed. Thus, the hydration degree of cement is higher and more pores can be filled by the new generated C-S-H gel [12]. UHPC possesses densified microstructures consequently, blocking the chloride from penetrating into the UHPC [13]. Previous studies also have proved that the chloride penetration into concrete containing pozzolanic materials such as silica fume, fly ash and blast furnace slag improved the microstructure and reduced the content of the harmful large pores [1, 14, 15]. An experimental study performed by Ghafari et al. [16] showed that the addition of nano silica to the UHPC leads to reduction chloride penetration. Similar trend was previously found that various nanoparticles used in concrete can improve and densify the cement matrix thus leading to improved permeability of chloride ions into concrete [17, 18].

Within the limited review, it is found that the introduction of nano materials as alternative cement replacement in UHPC enhance the chloride penetration characteristic in terms of chloride depth and chloride content. Commonly, the nano materials used are nano silica, nano clay and nano metakaolin as additive in UHPC. Limit research has found to produce UHPC by using nano metaclay as additive. Nano metaclay can offer more improvement in concrete and also as 
an alternative to other nano material. Nano metaclay underwent calcination process contributed to reduction in size thus increase surface area of nano particles as compared to non-calcination samples [19,20]. This effect donated to filler action by nano metaclay in densifying concrete properties [21]. On the other hand, nano clay after underwent the calcined process become reactive pozzolanic material due to highest production of $\mathrm{SiO}_{2}$ and $\mathrm{Al}_{2} \mathrm{O}_{3}$. The chemical and morphology examination on nano metaclay have been examined in previous studies [22]. This is the opportunity in this study to investigate the chloride transport properties in UHPC containing nano metaclay. In this present study, the statistical relationships among two (2) independent factors (compressive strength and percentage of nano metaclay) for the chloride content and chloride depth were assessed through response surface methodology (RSM). The RSM is a mathematical and statistical technique that is useful for the optimization and to predict the response of parameters and significance of all possible combination of interactions. The most common nonlinear empirical model is a second order polynomial of the design variable or also known as quadratic model. In the situation where two (2) variables combined, second order equation will be required [23].

\section{METHODOLOGY}

\section{Materials and Mix Proportion}

The basic components of cement, coarse aggregate, sand, water, and superplasticiser were mixed together by using dry mix method. In this study, four (4) series of concrete mix proportion were prepared. The prepared concretes were classified as ultra-high performance concrete (UHPC) and nano metaclayed-UHPC (NM-UHPC) incorporating three (3) different levels of nano metaclay as cement replacement. The different replacement levels of nano metaclay comprised of 1, 3 and 5\% from the total weight of Ordinary Portland cement used. The ranges of level replacement selected was adopted in [21] The commercially available nano clay powder (hydrophilic bentonite) was procured from Sigma-Aldrich (M) Sdn. Bhd. The raw nano clay samples were heated at the temperature of $700^{\circ} \mathrm{C}$ for 3 hours' process period. The calcination process is required for making the nano clay samples become reactive (nano metaclay) thus can react chemically with Portland cement. Table 1 shows the details of each concrete mix design. Mix constituent for UHPC was finalized based on trial mixes and adopted from previous work [21,22]. The water to cement ratio for UHPC was fixed at 0.20 . Since concrete mixes with a 0.20 water to cement ratio were produced, it was necessary to apply a high-range waterreducing (superplasticiser) commercial chemical admixture (Glenium®) supplied by BASF (M) Sdn. Bhd. to improve the workability of the concrete mixes. The amounts of superplasticizer used are different for each series of mix designation. This is because the target slump for fresh UHPC and NM-UHPC mixes were fixed to $120 \mathrm{~mm}$ to meet the flowability of fresh UHPC and NC-UHPC. Several trial dosages of superplasticizer were performed until the concrete mix achieved the targeted slump. The amount of superplasticizer used varies from 0.84 to $1.44 \%$ from the total weight of cementitious used. Obviously, the superplasticizer used is lower than the $2 \%$ amount allowed. When dealing with nano metaclay in concrete mixing, Mohd Norhasri et al. [21] recommended that the addition of admixture need to be adjusted and altered together with the nano particles. This is to ensure that problem such as low workability do not arise, which could result in poor performance of UHPC and NM-UHPC at later age. This finding has been reported in the previous work done by [22].

Table 1. Series of mix proportion for UHPC and Nano Metaclayed-UHPC (NM-UHPC)

\begin{tabular}{lcccccc}
\hline \multirow{2}{*}{$\begin{array}{l}\text { Mix } \\
\text { Designation }\end{array}$} & OPC & Nano metaclay & Aggregate & Sand & Water & Glenium® \\
\cline { 2 - 7 } UHPC & 800 & 0 & 433 & 800 & 160 & 11.52 \\
NM-UHPC1 & 792 & 8 & 433 & 800 & 160 & 6.70 \\
NM-UHPC3 & 776 & 24 & 433 & 800 & 160 & 6.98 \\
NM-UHPC5 & 760 & 40 & 433 & 800 & 160 & 7.60 \\
\hline
\end{tabular}

\section{Testing Procedures}

In this study, the concrete cube with dimensions of $100 \mathrm{~mm}$ x $100 \mathrm{~mm}$ x $100 \mathrm{~mm}$ and cylinder specimens with $100 \mathrm{~mm}$ diameter and $200 \mathrm{~mm}$ height were cast for compressive strength and chloride penetration test, respectively. After mixing, all test specimens were demoulded after 24 hours and then cured in water. The specimens for chloride penetration evaluation were taken out from water curing after cured for 7 days. Before exposed to sodium chloride $(\mathrm{NaCl})$ solution, the specimens were sealed at the top and bottom parts by applying waterproofing membrane type T-100 water-based PU bituminous to prevent the ingress of chloride ions at both parts. After the coating membrane dried, the specimens instantly immersed in $3 \% \mathrm{NaCl}$ solution for chloride exposure. The sodium chloride $(\mathrm{NaCl})$ with concentration of $3 \%$ was selected to simulate the aggressive environment. The concentration of $3 \% \mathrm{NaCl}$ solution was prepared based on percentage by weight-in-volume method. A concentration of $3 \%$ in aqueous solution is often used as a proxy for concentration of salt present in sea water [24]. All the specimens were immersed for 3, 7, 28, 56, 92, 182 and 365 days. At each interval of 
immersion, the concrete specimens were taken out and tested its chloride penetration namely chloride content and chloride depth. For chloride content for UHPC and modification NM-UHPC specimens, the concrete powder samples were test using $\mathrm{HACH}$ spectrophotometer and the test was conducted in accordance with Mercuric Thiocyanate Method (Method 8113)[25].

On the other hand, the chloride penetration depth profile of UHPC and a series of NM-UHPC specimens were determined by chemical method namely silver nitrate colorimetric method. The exposed specimens were prepared by splitting the samples axially into two (2) sections using compression machine. Then, the freshly fractured surfaces split of samples was sprayed with $0.1 \mathrm{M}$ silver nitrate $\left(\mathrm{AgNO}_{3}\right)$ solution and left in room temperature until sprayed solution was dried. Subsequently after the sprayed surface was completely dried, white silver chloride precipitation on the surface was visible. While, the area free of chloride ion remains natural or brown in colour. The penetration depth of the chloride penetrability was measured using digital calliper.

\section{Experimental Design and Analysis}

The Design Expert 6.0 software was used for the statistical design of data analysis and that is useful for developing, improving and optimizing process [26]. The most common nonlinear empirical model is a second order polynomial of the design variable or also known as quadratic RSM. RSM model can be visualised graphically being three-dimensional (3D) and it is helpful to see the formation shape of a response surface either hills, valleys or ridge lines. In the situation where two variables combined, second order equation are required [27]. A quadratic model equation for two variables is also known as second-order response surface model. This equation is flexible model to describe experimental data in which there is curvature.

In the present study, the experimental data and response surface methodology (RSM) were applied to optimize and assess the relationship among two significant independent variables: compressive strength, and percentage of nano metaclay as presented in Table 2. The label ' $A$ ' and ' $B$ ' was used to refer to the compressive strength, and percentage of nano metaclay, respectively. Chloride content and chloride depth were considered as the dependent factors (response). Performance of the process was evaluated by analyzing the chloride content and chloride depth efficiencies. Each independent variable was varied over three levels between -1 and +1 at the determined ranges based on a set of preliminary experiments. In RSM, the data analysis is conducted to perform the model fitting and validation. Considering that there are only three levels for each factor, the appropriate model is the quadratic model. The analysis of variance (ANOVA) was performed to obtain the interaction between the process variables an responses. In this study, the models generated and close to the observed value within the range of $95 \%$ confidence interval. The P-value approach is employed for hypothesis testing, that is, 'Prob $>$ F' less than 0.05 indicating that model terms are statically significant. The experimental designs with four (4) start points and seven (7) replicates at the central point had 28 experimental runs in the design are tabulated in Table 3.

Table 2. Factors and factor levels adopted for RSM

\begin{tabular}{lcccc}
\hline \multirow{2}{*}{ Variables } & Codes & \multicolumn{3}{c}{ Variable levels } \\
\cline { 3 - 5 } & & -1 & 0 & +1 \\
\hline Compressive strength $(\mathrm{MPa})$ & $\mathrm{A}$ & 92.76 & 113.75 & 132.79 \\
Percentage of nano metaclay $(\%)$ & $\mathrm{B}$ & 0 & 2.50 & 5 \\
\hline
\end{tabular}

Table 3. Two factor for experimental as well as responses of dependent variables

\begin{tabular}{cccccc}
\hline \multirow{2}{*}{ Run } & $\begin{array}{c}\text { Age } \\
(\text { Days })\end{array}$ & $\begin{array}{c}\text { A: Compressive } \\
\text { strength (MPa) }\end{array}$ & $\begin{array}{c}\text { B: Percentage of } \\
\text { nano metaclay }(\%)\end{array}$ & $\begin{array}{c}\text { Chloride } \\
\text { content (ppm) }\end{array}$ & $\begin{array}{c}\text { Chloride } \\
\text { depth (mm) }\end{array}$ \\
\hline 1 & 3 & 93.23 & 0 & 10.16 & 0.98 \\
2 & & 95.11 & 1 & 7.84 & 1.29 \\
3 & & 94.56 & 3 & 18.78 & 1.85 \\
4 & & 92.76 & 5 & 18.18 & 2.16 \\
5 & 7 & 95.33 & 0 & 17.96 & 2.32 \\
6 & & 103.20 & 1 & 16.44 & 2.39 \\
7 & 97.78 & 3 & 19.76 & 2.43 \\
\hline
\end{tabular}


Table 3. Two factor for experimental as well as responses of dependent variables (cont.)

\begin{tabular}{cccccc}
\hline \multirow{2}{*}{ Run } & $\begin{array}{c}\text { Age } \\
\text { (Days) }\end{array}$ & \multicolumn{2}{c}{ Factors } & Response 1 & Response 2 \\
\cline { 3 - 6 } & & strength (MPa) & $\begin{array}{c}\text { B: Percentage of } \\
\text { nano metaclay }(\%)\end{array}$ & $\begin{array}{c}\text { Chloride } \\
\text { content (ppm) }\end{array}$ & $\begin{array}{c}\text { Chloride } \\
\text { depth }(\mathrm{mm})\end{array}$ \\
\hline 8 & & 95.07 & 5 & 22.50 & 2.49 \\
9 & 28 & 100.14 & 0 & 22.16 & 4.29 \\
10 & & 109.98 & 1 & 20.00 & 3.83 \\
11 & & 100.71 & 3 & 26.72 & 4.59 \\
12 & & 97.35 & 5 & 33.22 & 4.69 \\
13 & 56 & 101.62 & 0 & 40.12 & 6.10 \\
14 & & 113.33 & 1 & 28.86 & 4.55 \\
15 & & 103.90 & 3 & 59.32 & 6.86 \\
16 & & 99.51 & 5 & 67.64 & 7.21 \\
17 & 91 & 110.68 & 0 & 52.56 & 7.28 \\
18 & & 125.20 & 1 & 35.83 & 6.59 \\
19 & & 109.22 & 3 & 67.40 & 8.12 \\
20 & & 102.99 & 5 & 69.30 & 8.86 \\
21 & 182 & 117.80 & 0 & 72.56 & 8.77 \\
22 & & 127.40 & 1 & 47.10 & 8.70 \\
23 & & 110.07 & 3 & 72.92 & 10.17 \\
24 & & 105.01 & 5 & 79.78 & 11.48 \\
25 & 365 & 119.80 & 0 & 82.94 & 7.11 \\
26 & & 134.79 & 1 & 67.34 & 5.27 \\
27 & & 113.33 & 59.24 & 10.70 \\
28 & & 108.86 & 102.72 & 11.02 \\
\hline
\end{tabular}

\section{EXPERIMENTAL RESULTS}

\section{Statistical Analysis using ANOVA}

The experimental result associated with the interaction between each independent variables is presented in Table 4 . The presented data was fitted to the proposed second degree polynomial using multiple linear regressions to determine the optimum conditions for the chloride transport properties that resulted in the UHPC and a series of NM-UHPC specimens. The effect of compressive strength and inclusion of nano metaclay content in UHPC were quantitatively evaluated using response surface curve. Table 4 presents a summary of the model validation parameters of response using variance of analysis (ANOVA). The coefficient of regression (R-squared) generated by RSM for chloride content was found to be 0.750 . The R-squared obtained representing a moderate relationship, which indicated that only $75 \%$ of the variability in chloride content can be attributed to its compressive strength and nano metaclay content. It is also observed that $\mathrm{A}, \mathrm{B}, \mathrm{A}^{2}, \mathrm{~B}^{2}$ and $\mathrm{AB}$ indicate the model terms are significant with a probability of $95 \%$. The model was verified that the model F-value of 13.16 generated by ANOVA implies the model is significant. There is only a $0.01 \%$ chance that the F-value this large could occur due to noise. Furthermore, the value of "Prob $>$ F" is less than 0.05 indicate model terms are significant. For chloride depth, the R-squared obtained is 0.856 explicates that the predicted values were found to be in good agreement with experimental values. In this case, the value of R-squared indicated that only $14.4 \%$ of the total variance was not explained by the developed regression model. As shown in Table 4, the ANOVA presented a model Fvalue of 26.04, indicating the model is significant. The values of "Prob $>F$ " for the models were statically significant at the stipulated level of 0.05 . Consequently, the model terms $\mathrm{A}, \mathrm{B}, \mathrm{A}^{2}, \mathrm{~B}^{2}$ and $\mathrm{AB}$ have significant interaction in the chloride depth.

In addition, "Adeq. Precision" measures the signal to noise ratio. The "Adeq. Precision" ratio of the model varies between 13.657 for chloride content and 18.970 for chloride depth, which is an adequate signal for the model. "Adeq. Precision" values higher than four (4) are desirable and confirm that the predicted model can be used to navigate the space checked by the ANOVA using RSM. Since the R-squared value is closer to one (1), it indicates that the regression 
perfectly fits. From the quadratic regression, the relation equation in term of actual factors is presented in Table 5 . All the generated quadratic models are shown in Equation 1 and Equation 2. In this study, two (2) quadratic models performed by ANOVA are significant model term. Values of "Prob $>$ F" recorded for the models are less than 0.050 indicate model term for both responses are significant. Insignificant model terms, which have limited influence, were excluded from the study to improve the models. To confirm the selected model provides an adequate approximation of the real system, the normal probability plots of the studentized residuals and diagnostics are provided by the Design Expert 6.0 software and it is presented in Figure 3. The normal probability models demonstrate the normal probability plots of the standardized residuals for chloride content and chloride depth as demonstrated in Figures 3(a) and (b), respectively. A normal probability plot indicates a straight line for each case. However, some scattering is expected even with the normal data. Accordingly, the data can be possibly considered as normally distributed in the responses of certain models.

Table 4. ANOVA for quadratic models of chloride transport properties

\begin{tabular}{|c|c|c|c|c|c|c|c|}
\hline Responses & Sources & $\begin{array}{l}\text { Sum of } \\
\text { squares }\end{array}$ & DF & $\begin{array}{l}\text { Mean } \\
\text { square }\end{array}$ & F value & Prob > F & Remarks \\
\hline \multirow[t]{10}{*}{ Chloride conten } & Model & 16110.16 & 5 & 3222.032 & 13.156 & $<0.0001$ & Significant \\
\hline & A & 5563.505 & 1 & 5563.505 & 22.716 & $<0.0001$ & Significant \\
\hline & B & 4361.497 & 1 & 4361.497 & 17.808 & 0.0004 & Significant \\
\hline & $\mathrm{A}^{2}$ & 1433.564 & 1 & 1433.564 & 5.853 & 0.0243 & Significant \\
\hline & $\mathrm{B}^{2}$ & 1666.003 & 1 & 1666.003 & 6.802 & 0.0161 & Significant \\
\hline & $\mathrm{AB}$ & 1455.559 & 1 & 1455.559 & 5.943 & 0.0233 & Significant \\
\hline & R-squared & 0.750 & & & & & \\
\hline & Std. deviation & 15.650 & & & & & \\
\hline & C.V \% & 34.251 & & & & & \\
\hline & deq. precision & 13.657 & & & & & \\
\hline \multirow[t]{10}{*}{ Chloride depth } & Model & 232.03 & 5 & 46.41 & 26.04 & $<0.0001$ & Significant \\
\hline & A & 62.13 & 1 & 62.13 & 34.87 & $<0.0001$ & Significant \\
\hline & B & 53.26 & 1 & 53.26 & 29.89 & $<0.0001$ & Significant \\
\hline & $A^{2}$ & 38.69 & 1 & 38.69 & 21.71 & 0.0243 & Significant \\
\hline & $\mathrm{B}^{2}$ & 19.60 & 1 & 18.10 & 10.16 & 0.0161 & Significant \\
\hline & $\mathrm{AB}$ & 39.20 & 1 & 19.60 & 11 & 0.0233 & Significant \\
\hline & R-squared & 0.856 & & & & & \\
\hline & Std. deviation & 1.330 & & & & & \\
\hline & C.V \% & 23.060 & & & & & \\
\hline & deq. precision & 18.970 & & & & & \\
\hline
\end{tabular}

Table 5. Prediction levels of chloride transport properties

\begin{tabular}{lrl}
\hline Responses (Model) & Final equations \\
\hline Chloride content (ppm) & $-795.41+14.06 A-69.17 B-0.05 A^{2}+3.15 B^{2}+0.59 A B$ & $(1)$ \\
Chloride depth (mm) & $-124.96+2.25 A-7.91 B-9.55 \times 10^{-3} A^{2}+0.33 B^{2}+0.07 A B$ & $(2)$ \\
\hline
\end{tabular}




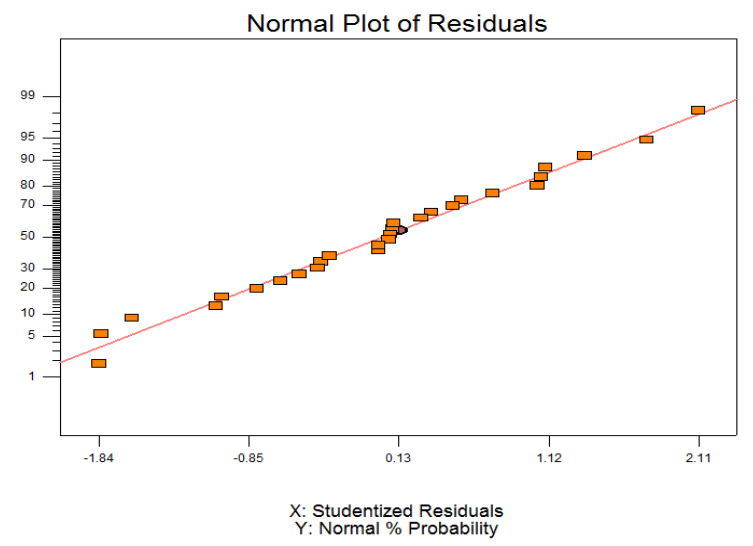

(a)

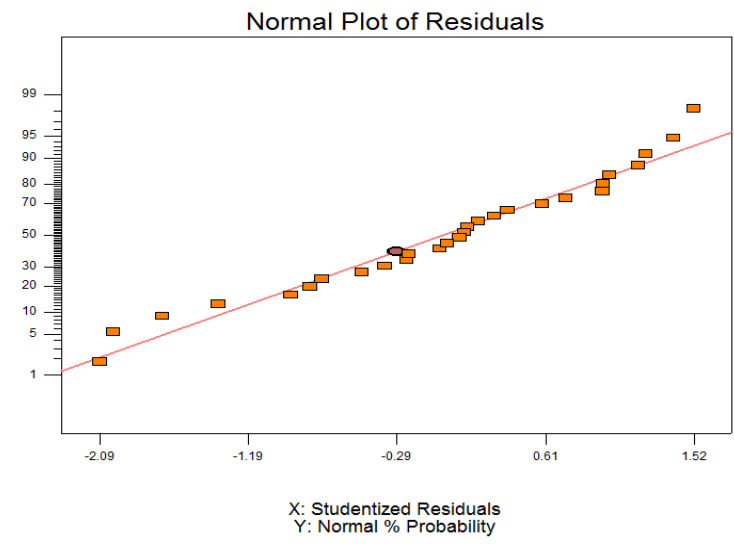

(b)

Figure 3. Normal probability plot of the studentized residuals for chloride content (a) and chloride depth (b)

\section{Relation between Compressive Strength and Nano Metaclay Content for Chloride Transport Properties}

The 3D surface of response plots is used to assess the interactive relationships between compressive strength and nano metaclay content against chloride content and chloride depth in UHPC. Similarly, the quadratic regression was designed by RSM to obtain the best fit for the relation. Instead, adequacy of the model was also tested by examining the perturbation trends by looking at the formal power series curve. Figure 4 depicts the 3D surface of response plots for evaluating the relationship between compressive strength and percentage of nano metaclay versus chloride content with respect to UHPC and a series of NM-UHPC. From RSM analysis, there is significant effect on the relationship between compressive strength and different percentage of nano metaclay against chloride content for UHPC based nano metaclay as shown in Figure 4(a). It shows that when the content of nano metaclay increased, the chloride content in NM-UHPC increased while the increase of compressive strength matched well with the decrease of chloride content. The plot clearly described that the chloride content in UHPC and NM-UHPC was influential by inclusion of nano metaclay in UHPC mixes. Concurrently, Figure 4(b) plotted the perturbation graph for optimum values of the tested variables. It is clearly revealed that a curvature for Curve B represents nano metaclay content indicated the sensitivity of the response factor. This means that inclusion of different level of nano metaclay in UHPC has significant effect and is a dominant factor contribute to the compressive strength and chloride resistance behavior.

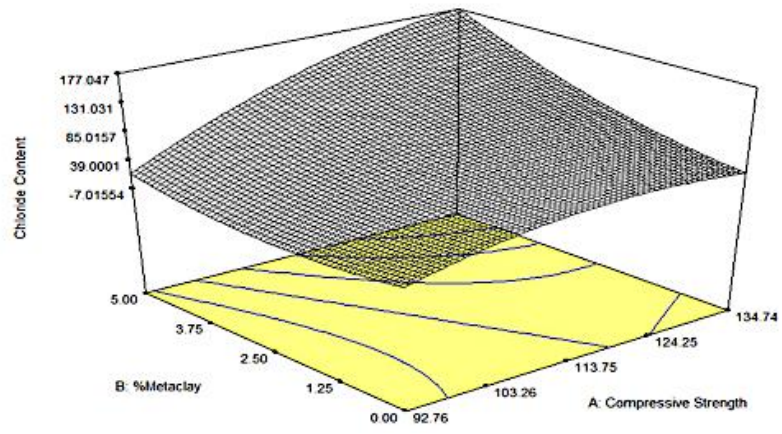

(a)

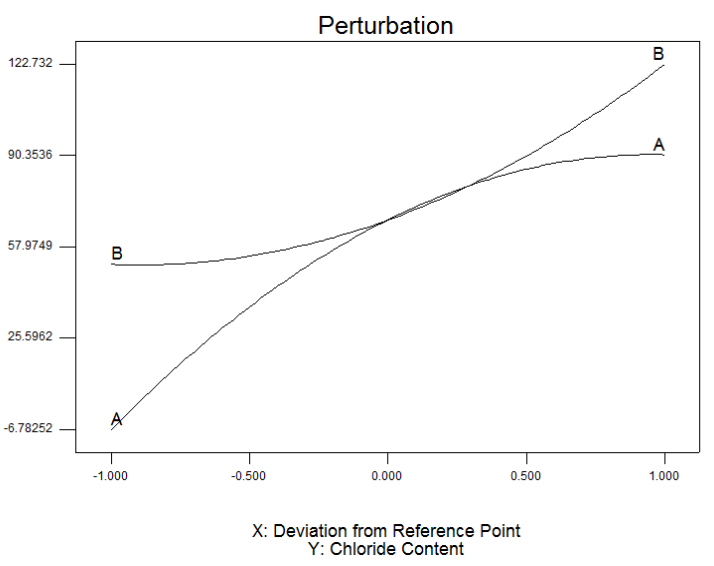

(b)

Figure 4. Response surface plot (a) and perturbation plot (b) for chloride content as a function of compressive strength and nano metaclay content $(\%)$

Figure 5 is used to evaluate the relationship between compressive strength and nano metaclay content against chloride depth in UHPC. The quadratic regression and perturbation plot were designed by RSM to obtain the best fit for the chloride depth relation with compressive strength and percentage of nano metaclay. Figure5(a) portrays the optimum values of the tested variables between compressive strength and percentage of nano metaclay in UHPC and NM-UHPC. The result clearly described that the chloride depth for UHPC and NM-UHPC was influential by inclusion of nano metaclay in UHPC mixes. The 3D surface response shows that when the content of nano metaclay increased, the chloride penetration depth of nano metaclayed-UHPC also increased. In opposition, when the increasing of compressive strength, the chloride penetration depth decreased. The steep slope in the perturbation plots in Figure 5(b) showed the Curve B for nano metaclay content indicated enhance the strength properties thus improve the chloride resistance of the resulted 
UHPC. The Curve A shows the sensitivity of the response factor influenced by compressive strength of UHPC and NMUHPC.

Considering all the RSM analysis, it can be found that the increase in compressive strength and decrease in nano metaclay content are the two (2) factors for improving chloride transport in UHPC. NM-UHPC1 marked the greatest chloride penetration resistant which the amount of chloride content that can penetrate into the UHPC1 is lower than those of UHPC and nano based UHPC incorporated 3 and 5\% of nano metaclay labelled as NM-UHPC3 and NM-UHPC5, respectively. It was also noted that the increment of nano metaclay content in UHPC would increase the amount of chloride that can penetrate into concrete. It is believed that inclusion of nano metaclay more than $3 \%$ in UHPC offers larger surface area to be covered with cement delaying the pozzolanic reaction. Therefore, UHPC5 specimen indicates the lowest chloride resistance among the NM-UHPC specimens. This finding was confirmed that an addition of $1 \%$ nano clay significantly improves the chloride penetration resistance of the resulted concrete [28]. An experimental study performed by Ghafari et al. [16] showed that the addition of nano silica to the UHPC leads to reduction of capillary pores. A finer microstructure would be expected to reduce the permeability thereby slowing the rate of chloride penetration [29, 30]. Similar trend was previously found by Ozyildirim and Zegetosky [17] and Abbas et al. [31] claimed that various nanoparticles used in concrete can improve and densify the cement matrix thus leading to improved permeability and strength of concrete. Furthermore, with an increase in curing periods of concrete, the formation of pozzolanic reaction in creating additional C-S-H gel refined the pores volume of concrete. Inclusion of lower replacement content of calcined clay in UHPC does not lead to refinement improvement of pore structure at early age [32]. The pozzolanic reaction which provides additional $\mathrm{C}-\mathrm{S}-\mathrm{H}$ gel started after 91 days and nucleation process of nano metaclay particles occurred at 180 days of age [33].

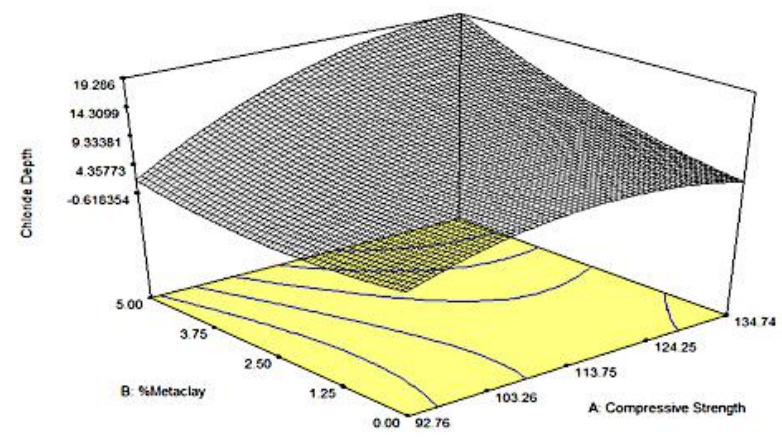

(a)

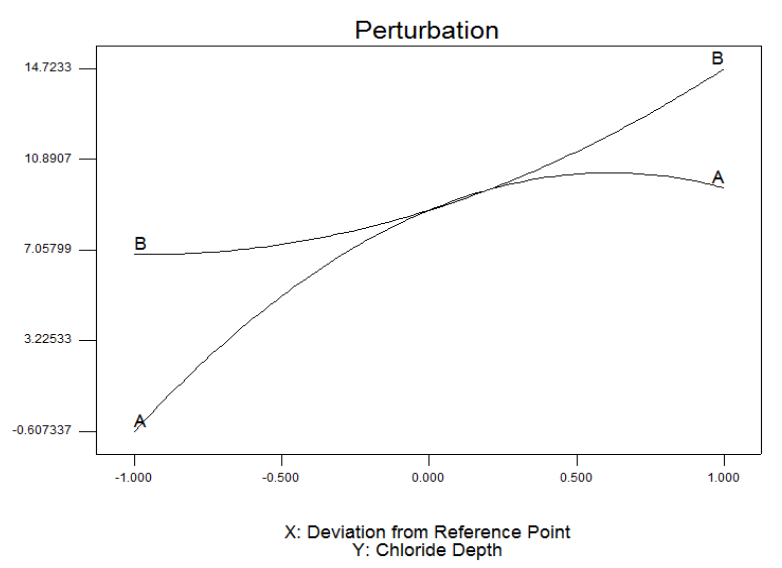

(c)

Figure 5. Response surface plot (a) and perturbation plot (b) for chloride depth as a function of compressive strength and nano metaclay content $(\%)$

\section{CONCLUSION}

This study investigated the chloride transport properties and demonstrated experimentally that inclusion of nano metaclay can be a potential for chloride penetration resistance for NM-UHPC. Findings of this study reveal the relationship between Factors (compressive strength and percentange of nano metaclay content) and Responses (chloride transport properties) for UHPC and a series of NM-UHPC. The followings are the conclusions from this study:

1. In this examination, it is showed that the use of $1 \%$ nano metaclay in UHPC marked superior in chloride transport properties and demonstrated better resistant characteristics against chloride content and chloride depth when compared to those of UHPC and UHPC incorporating 3 and 5\% nano metaclay.

2. ANOVA analysis and RSM also shows that the Factors have a significant effect on the chloride transport properties of NM-UHPC. Statistical analysis for the interaction of models' responses (chloride content and chloride depth) was significant at "Prob $>$ F" value less than 0.05 . Therefore, inclusion $1 \%$ nano metaclay has excellent potential as an alternative cement replacement for NM-UHPC.

3. It is hoped, this finding will encourage other researchers to discover more ways to make use the industrial or agricultural by-product for the benefits of mankind. It is recommended for future studies to look into other durability performance of nano metaclay based UHPC exposed to acidic, alkaline, elevated temperature and fire resistance. 


\section{ACKNOWLEDGEMENT}

The authors would like to thank the editors and anonymous reviewers whose invaluable comments and suggestions substantially helped improve this paper's quality. The author acknowledge the staff and team of technicians from the School of Civil Engineering, College of Engineering, UITM Shah Alam for their valuable help in facilitating and supporting the work.

\section{REFERENCES}

[1] S. Y. N. Chan, and C. Ji, "Comparative study of the initial surface absorption and chloride diffusion of high performance zeolite, silica fume and PFA concretes," Cement and Concrete Composite, vol. 21, pp. 293-300, 1999. https://doi.org/10.1016/S0958-9465(99)00010-4

[2] M. S. Muhd Norhasri, M. S. Hamidah, and A. Mohd Fadzil, "Morphology and strength of cement paste from clay as nano material," Applied Mechanics and Material, vol. 490-491, pp. 19-24, 2014. https://doi.org/10.4028/www.scientific.net/AMM.490-491.19

[3] M. S. Muhd Norhasri, M. S. Hamidah, and A. Mohd Fadzil, "Applications of using nano material in concrete: A review," Construction and Building Materials, vol. 133, pp. 91-97, 2017. https://doi.org/10.1016/j.conbuildmat.2016.12.005

[4] E. Ghafari, M. Arezoumandi, H. Costa, and E. Júlio, "Influence of nano-silica addition on durability of UHPC," Construction and Building Materials, vol. 94, pp. 181-188, 2015. https://doi.org/10.1016/j.conbuildmat.2015.07.009

[5] M. Stefanidou, E. C. Tsardaka, and E. Pavlidou, "Influence of nano-silica and nano-alumina in lime-pozzolan and limemetakaolin binders," Material Today: Proceeding, vol. 4, 7 (1), 2017. https://doi.org/10.1016/j.matpr.2017.07.020

[6] P. Zhang, J. Wan, K. Wang, and Q. Li, "Influence of nano- $\mathrm{SiO}_{2}$ on properties of fresh and hardened high performance concrete: A state-of-the-review," Construction and Building Materials, vol. 148, pp. 648-658, 2017. https://doi.org/10.1016/j.conbuildmat.2017.05.059

[7] K. Hong, and R. D. Hooton, "Effect of fresh water exposure on chloride contaminated concrete," Cement \& Concrete Research, vol. 30 (8), pp. 1561-1567, 2000. https://doi.org/10.1016/S0008-8846(00)00335-5

[8] C. Scheydt, and S. Müller, "Microstructure of ultra high performance concrete (UHPC) and its impact on durability," In Proceeding of the $1^{\text {st }}$ International Symposium on Ultra High Performance Concrete, Kassel, Germany, pp. 349-356, 2012.

[9] I. Ferdosian, and A. Camões, "Ultra-high durable concrete: A way towards safe and durable structure," In Proceeding of the $7^{\text {th }}$ International Conference on Safety and Durability of Structures, Portugal, 2016. http://hdl.handle.net/1822/43206

[10] J. Piérard, B. Dooms, and N. Cauberg, "Evaluation of durability parameters of UHPC using accelerated lab test," In Proceeding

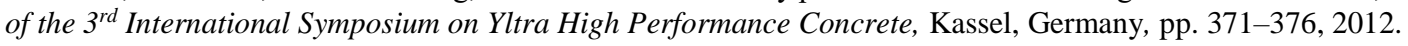

[11] R. Pernicová, "Chloride transport in ultra high performance concrete," World Academy of Science, Engineering and Technology International Journal of Materials and Metallurgical Engineering, vol. 8 (11), pp. 1192-1195, 2014. https://doi.org/10.5281/zenodo.1096663

[12] R. Yu, P. Spiesz, and H. J. H. Brouwers, "Effect of nano-silica on the hydration and microstructur development of ultra-high performance concrete (UHPC) with a low binder amount," Construction and Building Materials, vol. 65, pp. 140-150, 2014. https://doi.org/10.1016/j.conbuildmat.2014.04.063

[13] P. C. Aïtcin, "The durability characteristics of high performance concrete: A review," Cement and Concrete Composite, vol. 25 (4-5), pp. 409-420, 2003. https://doi.org/10.1016/S0958-9465(02)00081-1

[14] F. Leng, N. Feng, and X. Lu, "An experimental study on the properties of resistance to diffusion of chloride ions of fly ash and blast furnace slag concrete," Cement and Concrete Research, vol. 30 (6), pp. 989-992, 2000. https://doi.org/10.1016/S00088846(00)00250-7

[15] J. Lizarazo-Marriaga, and P. Claisse, "Modelling chloride penetration in concrete using electrical voltage and current approaches," Materials Research, vol. 14 (1), pp. 31-38, 2011. https://doi.org/10.1590/S1516-14392011005000008

[16] E. Ghafari, H. Costa, E. Júlio, E. Portugal, and L. Durães, "The effect of nanosilica addition on flowability, strength and transport properties of ultra high performance concrete," Material and Design , vol. 59, pp. 1-9, 2014. https://doi.org/10.1016/j.matdes.2014.02.051

[17] C. Ozyildirim, and C. Zegetosky, "Laboratory investigation of nanomaterials to improve the permeability and strength of concrete," Report FHWA/VTRC 10-R18 , Virginia Transportation Research Council, 2010. http://www.virginiadot.org/vtrc/main/online_reports/pdf/10-r18.pdf

[18] S. Abbas, M. L. Nehdi, and M. A. Saleem, "Ultra-high performance concrete: mechanical performance, durability, sustainability and implementation challenges," International Journal of Concrete Structures and Materials, vol. 10 (3), pp. 271-295, 2016. doi.10.1007/s40069-016-0157-4

[19] M. J. Mohd Faizal, M. S. Hamidah, M. S. Muhd Norhasri, I. Noorli, and M. P. Mohamad Ezad Hafez, "Chloride permeability of nanoclayed ultra-high performance concrete,” In: Hassan R., Yusoff M., Alisibramulisi A., Mohd Amin N., Ismail Z. (eds) InCIEC 2014, pp. 613-625, 2015 . Springer, Singapore. https://doi.org/10.1007/978-981-287-290-6_54

[20] M. S. Muhd Norhasri, M. S. Hamidah, A. Mohd Fadzil, M. J. Mohd Faizal, "Characteristic and Strength Properties of Nano Metaclayed UHPC”. In: Yusoff M., Hamid N., Arshad M., Arshad A., Ridzuan A., Awang H. (eds) InCIEC 2015, pp 689-697, 2016. Springer, Singapore. https://doi.org/10.1007/978-981-10-0155-0_58 
[21] M. S. Muhd Norhasri, M. S. Hamidah, and A. Mohd Arshad, "Inclusion of nano metaclayed as additive in ultra high performance concrete (UHPC)," Construction and Building Materials, vol. 201, pp. 590-598, 2019. https://doi.org/10.1016/j.conbuildmat.2019.01.006

[22] M. J. Mohd Faizal, M. S. Hamidah, M. S. Muhd Norhasri, M. Khairunisa, and I. Noorli, "Performance of nano metaclay on chloride diffusion for ultra-high performance concrete, " IOP Conf. Series: Earth and Environmental Science, 682, 012002, 2021. doi:10.1088/1755-1315/682/1/012002.

[23] R. V. Lenth, "Response-surface methods in R using RSM," Journal of Statistical Software, vol. 32 (7), pp. 1-7, 2009. http://dx.doi.org/10.18637/jss.v032.i07

[24] M. A. Sajjad, W. I. Wan Haziman, J. Norwati, A. Mohd fadzil, and S. Shahiron, "Performance of concrete containing coal bottom ash with different fineness as a supplementary cementitious material exposed to seawater," Journal of Statistical Software, vol. 32 (7), pp. 1-7, 2009. http://dx.doi.org/10.18637/jss.v032.i07

[25] Method 8113, Chloride. Mercuric thiocyanate method. DR5000 HACH Spectrophotometer procedure manual. 2005.

[26] R. H. Myers, D. C. Montgomery, and C. M. Anderson-Cook, "Response surface methodology: process and product optimization using designed experiments," $3^{\text {rd }}$ Edition, John Wiley \& Sons, 2016.

[27] K. M. Carley, N. Y. Kamneva, and J. Reminga, "Response surface methodology," Technical report, Pittsburgh, PA, 15213: Carnegie Mellon University, School of Computer Science, 2004. doi:http//www.casos.cu.cmu.edu/publications/papers/CMUISR-04-136.pdf.

[28] X. He, and X. Shi, "Chloride permeability and microstructure of Portland cement mortars incorporating nanomaterials," Transportation Research Record: Journal of the Transportation Research Board, No. 2070, pp. 13-21, 2008. https://doi.org/10.3141\%2F2070-03

[29] K. Kovler, and N. Roussel, "Properties of fresh and hardened concrete," Cement and Concrete Research, vol. 41, pp. 775-792, 2011. https://doi.org/10.1016/j.cemconres.2011.03.009

[30] V. Rahhal, V. Bonavetti, L. Trusilewicz, C. Pedrajas, and R. Talero, "Role of the filler on Portland cement hydration at early ages," Construction and Building Materials, vol. 27 (1), pp. 82-90, 2012. https://doi.org/10.1016/j.conbuildmat.2011.07.021

[31] S. Abbas, A. M. Soliman, and M. L. Nehdi, "Exploring mechanical and durability properties of ultra-high performance concrete incorporating various steel fibre lengths and dosages," Construction and Building Materials, vol. 75, pp. 429-441, 2015. https://doi.org/10.1016/j.conbuildmat.2014.11.017

[32] W. Huang, H. Kazemi-Kamyab, W. Sun, and K. Scrivener, "Effect of replacement of silica fume with calcined clay on the hydration and microstructure development of eco-UHPFRC," Material Design , vol. 121, pp. 36-46, 2017. https://doi.org/10.1016/j.matdes.2017.02.052

[33] M. S. Morsy, S. H. Alsayed, and M. Aqel, "Effect of nano-caly on mechanical properties and microstructure of Portland cement mortar," International Journal of Civil \& Environmental Engineering, vol. 10 (1), pp. 21-25, 2010. 